\title{
Genome Sequence Resource for Spiroplasma citri, Strain CC-2, Associated with Citrus Stubborn Disease in California
}

Raymond Yokomi, ${ }^{1, \dagger}$ Jianchi Chen, ${ }^{1}$ Rachel Rattner, ${ }^{1}$ Vijayanandraj Selvaraj, ${ }^{1}$, Yogita Maheshwari, Fatima Osman, ${ }^{2}$ Deborah Pagliaccia, ${ }^{3}$ and Georgios Vidalakis ${ }^{4}$

${ }^{1}$ United States Department of Agriculture-Agricultural Research Service, San Joaquin Valley Agricultural Sciences Center, Parlier, CA 93648

${ }^{2}$ Department of Plant Pathology, University of California, Davis, CA 95616

${ }^{3}$ Department of Botany \& Plant Sciences, University of California, Riverside, CA 92521

${ }^{4}$ Department of Microbiology and Plant Pathology, University of California, Riverside

\begin{abstract}
Spiroplasma citri is a bacterium that causes stubborn disease of citrus and infects other crops, ornamentals, and weeds. It is transmitted by leafhoppers in a circulative manner. Due to limited sequence data on $S$. citri, the bacterium was isolated from naturally infected Chinese cabbage grown on a farm in Fresno County, CA. DNA from S. citriCC-2 was extracted from a pure culture in LD8 and subjected to PacBio sequencing. Four contigs were obtained with a single circular chromosome of 1,709,192 bp and three plasmids of 40,210, 39,313, and 2,921 bp in size. The genome developed herein extends the sequence database of $S$. citri and is the first wholegenome sequence record of $S$. citri from California.
\end{abstract}

\section{Genome Announcement}

Spiroplasma citri (Bacteria; Tenericutes; Mollicutes; Entomoplasmatales; Spiroplasmataceae; Spiroplasma) is a phloem-limited, cell-wall-less, Gram-positive plant-pathogenic bacterium and has a wide host range. It infects many weed and ornamental plants; for example, London rocket (Sisymbrium irio), mustard (Brassica spp.), wild radish (Raphanus raphanistrum), periwinkle (Vinca rosea), Chinese aster (Callistephus chinensis), and Shasta daisy (Leucanthemum $\times$ superbum)] (Calavan and Bové 1989). Crop hosts include citrus (Citrus spp.). (Calavan and Bové 1989), horseradish (Armoracia rusticana, syn. Cochlearia armoracia) (Fletcher et al. 1981), carrot (Daucus carota subsp. sativus) (Lee et al. 2006), and sesame (Sesamum indicum) (Zarei et al. 2017), where it induces diseases such as citrus stubborn disease (CSD), horseradish brittleroot, carrot purple leaf, and putative sesame yellows, respectively. S. citri also infects leafhoppers such as Circulifer tenellus (Liu et al. 1983). and C. hematoceps (Breton et al. 2010), which transmit the pathogen from plant to plant in a circulative manner (Liu et al. 1983). In California, CSD is endemic and causes variable damage in citrus. In sweet orange (Citrus sinensis), symptoms include stunted growth; shortened internodes; chlorotic leaves; small upturned leaves; off-season flowering; and small, misshaped, and stylar-end greening of fruit (Yokomi et al. 2008), resulting in reduced fruit yield and quality (Mello et al. 2010).

A genome sequence of Spiroplasma citri strain R8-A2, collected originally from Morocco, has been reported with a 1,599,709-bp circular chromosome and two plasmids of 26,182 and

${ }^{\dagger}$ Corresponding author: R. Yokomi; ray.yokomi@usda.gov

The author(s) declare no conflict of interest.

Accepted for publication 3 September 2019.

This article is in the public domain and not copyrightable. It may be freely reprinted with customary crediting of the source. The American Phytopathological Society, 2020.
Funding

This work was supported by the United States Department of Agriculture (USDA) 2034-22000-013-10R and two grants from the Citrus Research Board (project 5300-191 to R. Yokomi and project 5100153 to $\mathrm{G}$. Vidalakis). Additional support for this work was provided, in part, by the Citrus Research Board (project 6100), the USDA National Institute of Food and Agriculture, Hatch project 233744, and the National Clean Plant Network (AP17PPQS\&T00C118 and AP18PPQS\&T00C107). The sequencing was carried out at the DNA Technologies and Expression Analysis Cores at the UC Davis Genome Center, supported by NIH Shared Instrumentation Grant 1S100D010786-01. 
14,987 bp in size (Davis et al. 2017). The purpose of the present research was to sequence a S. citri strain from California.

Using LD8 medium (Lee and Davis 1984), S. citri strain CC-2 was isolated in August 2016 from Chinese cabbage (Brassica rapa subsp. pekrnensis) from a production farm in Fresno County, CA and maintained in culture. For sequencing, S. citri strain CC-2 was triple cloned and cultured in LD8 medium at $30^{\circ} \mathrm{C}$ for $48 \mathrm{~h}$ and repeated to obtain enough DNA for sequencing. Total genomic DNA was extracted using the cetyltrimethylammonium bromide method (Doyle 1991).

Whole-genome sequencing of S. citri CC-2 was performed on the PacBio (Menlo Park, CA, U.S.A.) RS II platform using single-molecule real-time (SMRT) cell v3 with sequencing polymerase $(\mathrm{P})$ and chemistry 4.0 v2-P6C4. The library was prepared using the PacBio procedure for preparing $>30-\mathrm{kb}$ libraries using the SMRTbell Express Template Preparation Kit, according to the manufacturer's specifications. Adapter screening and quality filtering of raw sequencing data were performed using SMRT Analysis (PacBio) with default settings. The CC-2 genome yielded 92,698 reads encompassing $1,420,555,954 \mathrm{bp}$. The scaffold length at which $50 \%$ of the total assembly length is covered was $21,520 \mathrm{bp}$.

The assembly of contigs from subreads was generated using Canu 1.8 (Koren et al. 2017). Four contigs were obtained (Table 1). To check for contig circularity, approximately 500-bp segments from each end of a contig were used to BLAST search PacBio read data. Appropriate reads connecting both ends were used for enclosure. Contig 1 was determined to be a chromosome because of its size of 1,709,192 bp, similar to the S. citri R8-A2 strain (Davis et al. 2017). Contigs 2, 3 , and 4 were assigned to be plasmids because of their sizes of 40,210 , 39,313 , and 2,921 bp, respectively (Table 1). The chromosome and plasmid status of each contig was further confirmed by BLAST analyses against the GenBank database. All four contigs had top hits to $S$. citri (Table 1). Annotation of each contig was performed by the NCBI Prokaryotic Genome Annotation Pipeline (Tatusova et al. 2016). Related metrics are presented in Table 1. These data extend the $S$. citri genome sequence database from that previously reported (Davis et al. 2017) and is the first from California.

Data availability. The whole-genome sequences reported here have been deposited in DDBJ/ENA/GenBank under the accession numbers CP042472 for contig 1, CP042473 for contig 2, CP042474 for contig 3, and CP042475 for contig 4. The versions described in this article are the first versions. PacBio sequencing reads in this study have been deposited in the NCBI Sequence Read Archive under accession number SRR9903453 and in BioProject PRJNA558054. S. citristrain CC-2 has been deposited in the American Type Culture Collection under number SD-7278.

\section{Acknowledgments}

We thank R. DeBorde of the United States Department of Agriculture (USDA) Agricultural Research Service, San Joaquin Valley Agricultural Sciences Center, Parlier, CA for technical assistance. Mention of trade names or commercial products in this publication is solely for providing specific information and does not imply recommendation or endorsement by the USDA. USDA is an equal opportunity provider and employer.

Table 1. Spiroplasma citri CC-2 draft genome sequence

\begin{tabular}{|c|c|c|c|c|c|c|c|c|c|c|}
\hline \multirow[b]{2}{*}{ Contig } & \multirow[b]{2}{*}{ Status $^{a}$} & \multirow[b]{2}{*}{ Size (bp) } & \multirow[b]{2}{*}{ Coverage } & \multirow[b]{2}{*}{ GC } & \multirow[b]{2}{*}{ ORF $^{b}$} & \multirow[b]{2}{*}{ Gene $^{c}$} & \multicolumn{4}{|c|}{ GenBank BLAST results } \\
\hline & & & & & & & Top hit & $Q C^{d}$ & ID (\%) ${ }^{\mathrm{e}}$ & Accession $^{f}$ \\
\hline 1 & Chr & $1,709,192$ & 1,062 & 25.6 & 1,944 & 38 & Strain R8-A2 & 97 & 99.91 & CP013197.1 \\
\hline 2 & Plasmid & 40,210 & 37 & 27.7 & 44 & 0 & pSci5 & 82 & 95.71 & AJ969073.1 \\
\hline 4 & Plasmid & 2,921 & 19 & 23.3 & 5 & 0 & pSciA & 95 & 97.76 & AJ966734.1 \\
\hline Sum & $\ldots$ & $1,791,636$ & $\ldots$ & $\ldots$ & $\ldots$ & $\ldots$ & $\ldots$ & $\ldots$ & $\ldots$ & $\ldots$ \\
\hline
\end{tabular}

a Genomic status; Chr = chromosome.

b Open reading frame.

c RNA gene.

d Query cover.

e Identity.

${ }^{f}$ Reference accession. 


\section{Literature Cited}

Breton, M., Duret, S., Danet, J.-L., Dubrana, M.-P., and Renaudin, J. 2010. Sequences essential for transmission of Spiroplasma citri by its leafhopper vector, Circulifer haematoceps, revealed by plasmid curing and replacement based on incompatibility. Appl. Environ. Microbiol. 76:3198-3205.

Calavan, E. C., and Bové, J. M. 1989. Ecology of Spiroplasma citri. Pages 425-484 in: The Mycoplasmas, Vol. 5: Spiroplasmas, Acholeplasmas, and Mycoplasms of Plants and Arthropods. R. F. Whitcomb and J. G. Tully, eds. Academic Press, London, U.K.

Davis, R. E., Shao, J., Zhao, Y., Gasparich, G. E., Gaynor, B. J., and Donofrio, N. 2017. Complete genome sequence of Spiroplasma citri strain R8-A2 ${ }^{\top}$, causal agent of stubborn disease in Citrus species. Genome Announce. 5:e00206-17.

Doyle, J. J. 1991. DNA protocols for plants. Pages 283-293. In: Molecular Techniques in Taxonomy. G. M. Hewitt, A. W. B. Johnson, and J. P. W. Young, eds. NATO ASI Series, Vol. 57. Springer-Verlag, Berlin, Germany.

Fletcher, J., Schultz, G. A., Davis, R. E., Eastman, C. E., and Goodman, R. M. 1981. Brittle root disease of horseradish: Evidence for an etiological role of Spiroplasma citri. Phytopathology 71:1073-1080.

Koren, S., Walenz, B. P., Berlin, K., Miller, J. R., Bergman, N. H., and Phillippy, A. M. 2017. Canu: Scalable and accurate long-read assembly via adaptive $k$-mer weighting and repeat separation. Genome Res. 27:722-736.
Lee, I.-M., Bottner, K. D., Munyaneza, J. E., Davis, R. E., Crosslin, J. M., du Toit, L. J., and Crosby, T. 2006. Carrot purple leaf: A new spiroplasmal disease associated with carrots in Washington State. Plant Dis. 90:989-993.

Lee, I.-M., and Davis, R. E. 1984. New media for rapid growth of Spiroplasma citri and corn stunt Spiroplasma. Phytopathology 74:84-89.

Liu, H.-Y., Gumpf, D. J., Oldfield, G. N., and Calavan, E. C. 1983. The relationship of Spiroplasma citri and Circulifer tenellus. Phytopathology 73:585-590.

Mello, A. F. S., Yokomi, R. K., Payton, M. E., and Fletcher, J. 2010. Effect of citrus stubborn disease on navel orange production in a commercial orchard in California. J. Plant Pathol. 92:429-438.

Tatusova, T., DiCuccio, M., Badretdin, A., Chetvernin, V., Nawrocki, E. P., Zaslavsky, L., Lomsadze, A., Pruitt, K. D., Borodovsky, M., and Ostell, J. 2016. NCBI prokaryotic genome annotation pipeline. Nucleic Acids Res. 44: 6614-6624.

Yokomi, R. K., Mello, A. F. S., Saponari, M., and Fletcher, J. 2008. Polymerase chain reaction-based detection of Spiroplasma citri associated with citrus stubborn disease. Plant Dis. 92:253-260.

Zarei, Z., Salehi, M., Azami, Z., Salari, K., and Bevén, L. 2017. Stubborn disease in Iran: Diversity of Spiroplasma citri strains in Circulifer haematoceps leafhoppers collected in sesame fields in Fars Province. Curr. Microbiol. 74: 239-246. 